\title{
Association between glucose-lowering drugs and circulating insulin antibodies induced by exogenous insulin therapy in patients with type 2 diabetes
}

Peng Zhang ( $\sim$ pengzhang1238@126.com)

Nanjing First Hospital

Yun Shen

Nanjing First Hospital

Xiao Hua Xu

Nanjing First Hospital

Bo Ding

Nanjing First Hospital

Reng-Na Yan

Nanjing First Hospital

Hui-Ying Wang

Nanjing First Hospital

Xiao-Jing Xie

Nanjing First Hospital

Jian-hua Ma

Nanjing First Hospital

Yun $\mathrm{Hu}$

Nanjing First Hospital

\section{Research Article}

Keywords: insulin antibodies, insulin therapy, glucose-lowering drugs, glargine

Posted Date: February 23rd, 2022

DOI: https://doi.org/10.21203/rs.3.rs-1345032/v1

License: (a) (1) This work is licensed under a Creative Commons Attribution 4.0 International License. Read Full License 


\section{Abstract}

Aim: Insulin antibodies (IAs) affects blood glucose control in patients using insulin therapy. We aim to investigate the association between different glucose-lowering treatments and IAs in patients with type 2 diabetic mellitus (T2DM).

Methods: In this cross-sectional, retrospective study, patients with T2DM who were using exogenous insulin therapy were included. All the patients had stable antidiabetic therapy in the last 3 months and measured IA levels using the iodine-125 array.

Results: A total of 1863 patients were enrolled. There were 902 (48.4\%) patients with positive IAs (IA level >5\%), and the mean IA level was $11.06(10.39,11.72) \%$. IA level was positively correlated with fasting blood glucose $(\mathrm{OR}=1.069, p<0.001)$. The proportion of positive IAs was lowest in patients using glargine only (31.9\%) and highest in patients using human insulin only (70.3\%), $p<0.001$. The IA levels in patients using sulfonylureas/glinides (8.3\%), metformin (9.6\%), and DPP-4 inhibitors (8.2 \%) were all lower than in patients without these drugs $(p$ all $<0.05$ ).

Conclusions: IA levels should be measured in patients with long-term insulin therapy. Insulin glargine and the combination of oral glucose-lowering drugs should be considered in IA positive patients.

\section{Introduction}

Many patients with type 2 diabetes mellitus (T2DM) eventually require and benefit from insulin therapy once progression of the disease overcomes the effect of oral agent [1]. Insulin antibodies (IAs), which were found commonly developed in patients treated with exogenous insulin, might affect glycemic control due to their tendency to bind and/or release insulin in an unpredictable fashion [2-4]. Recently, Zhu J et al, showed that higher circulating IA titer was associated with increased glycemic variability and risk of hypoglycemia [5], which were considered as potential risk factors for mortality [6] and diabetes complication in patients with $\operatorname{T2DM}[7,8]$. Therefore, it is important for endocrinologists to assess IA levels in patients with insulin therapy. Moreover, identifying the factors that influence IA levels may help us to further understand blood glucose fluctuations and improve blood glucose control in patients with diabetes.

Along with the development of recombinant human insulin and insulin analogues, several studies found that circulating IA levels is closely related to the mode of insulin injection and the types of insulin [9-11]. IA levels usually increased during first 12 weeks following initiation of exogenous insulin treatment and then stabilized or gradually declined[10, 12]. However, previous studies usually compared IA levels between patients using two types of insulin that act similarly. The different effects of all the types of insulin currently being used, as well as oral glucose-lowering drugs on IA have not been reported yet as we aware of.

Therefore, we analyzed the circulating IA levels in patients with T2DM using different insulin therapies and oral glucose-lowering drugs retrospectively in this study.

\section{Materials And Methods}

Study design

This was a retrospective, cross-sectional study, and was approved by the Institutional Ethical Committee of Nanjing First Hospital, Nanjing Medical University (KY20190926-01). The methods were conducted in accordance with the Declaration of Helsinki guidelines, including any relevant details. The need for informed consent was waived for the present study as the research involves no more than minimal risk to subjects, and the waiver did not adversely affect the rights and welfare of the subjects. All data was retrospectively collected from the medical review database without involving any identifiable private information under the consent of the corresponding department.

Two researchers extracted data from consecutive medical records of patients admitted to Nanjing First Hospital. Data analysis covered the period from Jan 2017 to Jan 2019. The inclusion criteria were as follows: 1) patients who were diagnosed with T2DM;

2) patients were using insulin therapy, and there are no changes in glucose-lowering drugs in the last 3 months before the end of index date; 3) IA levels was tested. Patients were excluded if they 1) had infectious diseases which may promote autoimmune responses[13]; 2) had acute complications of diabetes on admission, such as diabetic ketoacidosis and lactic acidosis, which

Page $2 / 13$ 
affect serum IA concentration through dehydration; 3) had severe systemic diseases or any other conditions that may influence IA levels; 4) pregnant; 5) used systemic glucocorticoid in the last 3 months.

Clinical and laboratory assessments

Patient data regarding height, weight, age, duration of diabetes, hypoglycemic treatment and other medication use were collected at the time of hospital admission. Body mass index (BMI) was calculated as weight divided by the square of height $\left(\mathrm{kg} / \mathrm{m}^{2}\right)$. Blood samples of all patients were collected after overnight fasting $(>10 \mathrm{~h})$. HbA1c was measured using high-performance liquid chromatography assay (Bio-Rad Laboratories, Inc. CA, USA). C-peptide was measured using chemiluminescent immunometric assay which employs the Modular Analytics E170 (Roche® Diagnostics GmbH, Mannheim, Germany).

The IA titers were determined using the iodine-125 insulin antibody array kit (Beijing North Institute of Biological Technology, China) in accordance with the manufacturer's instructions, the procedure being similar to that in the previous studies $[5,14]$. In brief, the serum sample $(100 \mu \mathrm{l})$ was diluted with buffer and then incubated with mono-${ }^{125}$ (TyrA 14) human insulin (1.1 kbp, $\left.100 \mu \mathrm{l}\right)$. After incubation at $37^{\circ} \mathrm{C}$ for $2 \mathrm{~h}$, bound and free insulin fractions were separated by polyethylene glycol. The results were expressed in terms of bound radioactivity in the precipitate as a percentage of total counts (\%B/T) in the assay. Blank values obtained by measurement of specific IA-zero serum were subtracted from sample values. IA $\leq 5 \%$ was identified as a negative result, and IA > $5 \%$ as positive[5]. The tests of IA levels were performed in Nanjing Clinical Nuclear Medicine Center (ISO/IEC15189/17020). The nonspecific binding rate should $\leq 15 \%$, the binding rate with standard IA positive serum should $>25 \%$, and the binding rate with standard negative serum should $<5 \%$. The intra- and inter-assay coefficients of variation were $<10 \%$ and $<15 \%$, respectively.

\section{Statistical analysis}

Statistical analyses were performed using the SPSS software (SPSS, Science, Chicago, USA). All variables were tested for normal distribution. Data are presented as means $(95 \% \mathrm{Cl})$. Insulin resistance and $\beta$-cell function were evaluated using Homeostasis Model Assessment 2 (HOMA2-IR and HOMA2- $\beta$ ), which were calculated using fasting C-peptide and blood glucose by HOMA2 Calculator

[15]. Differences between the positive and negative IA groups were examined using the student's unpaired $t$-test for parametric data or the Mann-Whitney U-test for non-parametric data, respectively. Logistics regression analysis was used to find the factors which may affect IA levels. Then the difference of IA levels among different blood glucose lowering drugs were analyzed using the analysis of covariance (ANCOVA) to adjusted the influence factors. The categorical data were examined with chi-square test. All comparisons were 2 -sided at a $5 \%$ significance level. A $p$ value $<0.05$ was considered to be statistically significant.

\section{Results}

Study populations

Among 7426 patients with T2DM, a total of 2496 (33.61\%) patients were using insulin therapy. Among these patients, two pregnant patients, two patients using systemic glucocorticoid, another 22 patients with changes in their lowering glucose drugs treatment in the last 3 months, and 134 patients with infection were excluded. Moreover, a hundred patients with positive glutamate decarboxylase antibody (GAD-Ab) were excluded. A total of 1863 patients completed IA measurement and were finally enrolled for analysis. There were 902 (48.4\%) patients with IA > 5\% (Fig. 1), and the mean IA level was $11.06(10.39,11.72) \%$.

Clinical characteristics of the patients with positive IAs.

Compared with patients with negative IA (IA $\leq 5 \%)$, patients with positive $I A s(I A>5 \%)$ was associated with higher age, diabetic duration, total cholesterol, low density lipoprotein-cholesterol (LDL-C), high density lipoprotein-cholesterol (HDL-c), fasting blood glucose (FBG), insulin levels, GAD-Ab levels, and the proportion of cancer. Alanine transferase (ALT), triglyceride and the proportion of smoking was lower in patients with IA $>5 \%$ than in the others (Table 1). To increase the specificity of IA, and reduce the ratio of false positive and false negative, we also analyzed the characteristics of patients with $I A>10 \%$ and $I A<1 \%$. The further analysis showed that the differences of age, ALT, total cholesterol, triglyceride, LDL-C, FBG, insulin levels, GAD-Ab, and the proportion of smoking and the complication of cancer between patients with IA $>10 \%$ and $\leq 1 \%$ were enlarged. Moreover, HOMA2-IR was higher 
in patients with $\mathrm{IA}>10 \%$ than in patients with $\mathrm{IA} \leq 1 \%$. HbA1c seemed also higher (but not statistically significant) in patients with IA $>10 \%$. The prevalence of diabetic complications between the patients with positive and negative IA were all similar (Table 1). 
Table 1

Clinical characteristics

\begin{tabular}{|c|c|c|c|c|c|c|}
\hline & $\begin{array}{l}I A \leq 5 \% \\
(n=961)\end{array}$ & $\begin{array}{l}I A>5 \% \\
(n=902)\end{array}$ & $\begin{array}{l}p \\
\text { value }\end{array}$ & $\begin{array}{l}I A \leq 1 \% \\
(n=278)\end{array}$ & $\begin{array}{l}I A>10 \% \\
(n=581)\end{array}$ & $\begin{array}{l}p \\
\text { value }\end{array}$ \\
\hline Age (year) & $63.1(62.3,63.9)$ & $64 \cdot 5(63 \cdot 7,65.2)$ & 0.029 & $62.6(61.1,64.2)$ & $65.4(64.5,66.4)$ & 0.004 \\
\hline $\begin{array}{l}\text { Gender (male } \\
\% \text { ) }\end{array}$ & $532(55.4)$ & $472(52.3)$ & 0.193 & $155(55.8)$ & 293(50.4) & 0.175 \\
\hline Smoking (\%) & 176(18.3) & $120(13.3)$ & 0.003 & $69(24.8)$ & $68(11.7)$ & $<0.001$ \\
\hline $\begin{array}{l}\text { Family history } \\
(\%)\end{array}$ & $219(22.8)$ & 187(20.7) & 0.287 & $71(25.5)$ & $121(20.8)$ & 0.145 \\
\hline BMI (kg/m2) & $24.8(24.6,25)$ & $24.8(24.6,25)$ & 0.998 & $24.6(24.2,25.1)$ & $24.7(24.4,25.0)$ & 0.854 \\
\hline $\begin{array}{l}\text { Diabetic } \\
\text { duration (year) }\end{array}$ & $12.6(12.1,13)$ & $13.4(12.9,13.8)$ & 0.012 & $13.3(12.5,14.2)$ & $13.6(13.0,14.1)$ & 0.687 \\
\hline $\operatorname{ALT}(g / L)$ & $26.7(24.5,28.9)$ & $23 \cdot 5(21 \cdot 9,25.1)$ & 0.049 & $30.4(26.0,34.7)$ & $23.8(21.6,25.9)$ & $<0.001$ \\
\hline AST $(g / L)$ & $20.7(19.3,22.2)$ & $18.9(18,19.7)$ & 0.691 & $21.7(19.0,24.4)$ & $19.1(18.1,20.2)$ & 0.513 \\
\hline $\begin{array}{l}\text { Creatinine } \\
(\mu \mathrm{mol} / \mathrm{L})\end{array}$ & $77.3(74.7,80)$ & $80.1(76.9,83.3)$ & 0.475 & 79.3(73.7,84.8) & $78.9(75.4,82.3)$ & 0.820 \\
\hline $\begin{array}{l}\text { Uric Acid } \\
(\mu \mathrm{mol} / \mathrm{L})\end{array}$ & $308.5(302.2,314.8)$ & $307.6(300.1,315)$ & 0.361 & $310.8(299.4,322.2)$ & $302.3(293.1,311.5)$ & 0.083 \\
\hline $\begin{array}{l}\text { Total } \\
\text { cholesterol } \\
\text { (mmol/L) }\end{array}$ & $4.7(4.4,5.1)$ & $4.8(4.4,5.1)$ & 0.032 & $4.3(4.1,4.4)$ & $4.6(4.4,4.8)$ & 0.004 \\
\hline $\begin{array}{l}\text { Triglyceride } \\
\text { (mmol/L) }\end{array}$ & $2(1.9,2.2)$ & $1.8(1.7,1.9)$ & 0.058 & $2.3(1.8,2.7)$ & $1.7(1.5,1.8)$ & 0.015 \\
\hline $\begin{array}{l}\text { LDL-c } \\
(\mathrm{mmol} / \mathrm{L})\end{array}$ & $2(2,2.1)$ & 2.1(2.1,2.2) & 0.003 & $1.8(1.7,1.9)$ & $2.2(2.1,2.2)$ & $<0.001$ \\
\hline $\begin{array}{l}\text { HDL-C } \\
(\mathrm{mmol} / \mathrm{L})\end{array}$ & $1.2(1.2,1.2)$ & $1.2(1.2,1.3)$ & 0.053 & $1.2(1.2,1.3)$ & $1.3(1.2,1.3)$ & 0.675 \\
\hline $\begin{array}{l}\text { White blood } \\
\text { cell }\left(\times 10^{9}\right)\end{array}$ & $6(5.9,6.1)$ & $6(5.9,6.1)$ & 0.984 & $5.9(5.8,6.1)$ & $6.0(5.9,6.1)$ & 0.922 \\
\hline $\begin{array}{l}\text { Neutrophil } \\
\text { ratio (\%) }\end{array}$ & $59.4(58.6,60.1)$ & $59.6(58.9,60.4)$ & 0.829 & $58.7(57.3,60.1)$ & $59.6(58.7,60.6)$ & 0.339 \\
\hline $\begin{array}{l}\text { Hemoglobin } \\
(\mathrm{g} / \mathrm{L})\end{array}$ & $130.5(129,132)$ & $129.2(127.9,130.5)$ & 0.315 & 129.7(127.6,131.8) & $128(126.5,129.5)$ & 0.248 \\
\hline FBG (mmol/L) & $8.4(8.2,8.7)$ & $9.1(8.8,9.4)$ & $\begin{array}{l}< \\
0.001\end{array}$ & $7.9(7.5,8.3)$ & $9.0(8.7,9.4)$ & $<0.001$ \\
\hline $\begin{array}{l}\text { Fasting Insulin } \\
(\mathrm{mU} / \mathrm{L})\end{array}$ & $22.2(18.9,25.6)$ & $41.4(34.2,48.6)$ & $<0.001$ & $27.4(21.5,33.2)$ & $54.0(43.8,64.3)$ & $<0.001$ \\
\hline $\begin{array}{l}\text { Insulin-120min } \\
(\mathrm{mU} / \mathrm{L})\end{array}$ & $54.4(49,59.7)$ & $93(79,107)$ & $\begin{array}{l}< \\
0.001\end{array}$ & $60.7(52.7,68.7)$ & $115.6(96.2,134.9)$ & $<0.001$ \\
\hline $\begin{array}{l}\text { Fasting CP } \\
(\mathrm{ng} / \mathrm{ml})\end{array}$ & $1.5(1.3,1.6)$ & $1.4(1.3,1.5)$ & 0.451 & $1.4(1,1.8)$ & $1.4(1.3,1.5)$ & 0.049 \\
\hline
\end{tabular}

Data are mean $(95 \% \mathrm{Cl})$ or number (percentage). IA, insulin antibody; BMI, body mass index; ALT, Alanine transferase; AST, Aspartate transferase; LDL-c, low density lipoprotein cholesterol; HDL-c, high density lipoprotein cholesterol; FBG, fasting blood glucose; CP, C peptide; HOMA2-IR, homeostasis model assessment 2 of insulin resistance; HOMA2- $\beta$, homeostasis model assessment 2 of $\beta$ cell function. HbA1c, hemoglobin; GAD-Ab, glutamic acid decarboxylase antibody. 


\begin{tabular}{|c|c|c|c|c|c|c|}
\hline & $\begin{array}{l}I A \leq 5 \% \\
(n=961)\end{array}$ & $\begin{array}{l}I A>5 \% \\
(n=902)\end{array}$ & $p_{\text {value }}$ & $\begin{array}{l}I A \leq 1 \% \\
(n=278)\end{array}$ & $\begin{array}{l}I A>10 \% \\
(n=581)\end{array}$ & $\begin{array}{l}p \\
\text { value }\end{array}$ \\
\hline $\begin{array}{l}\text { CP-120min } \\
(\mathrm{ng} / \mathrm{ml})\end{array}$ & $3.1(3,3.3)$ & $3(2.9,3.2)$ & 0.361 & $3.0(2.7,3.3)$ & $3.0(2.8,3.1)$ & 0.569 \\
\hline HOMA2-IR & $1.5(1.4,1.6)$ & $1.7(1.5,2)$ & 0.191 & $1.3(1.2,1.4)$ & $1.7(1.5,2)$ & 0.025 \\
\hline HOMA2- $\beta$ (\%) & $49.1(46.3,51.8)$ & $46.6(43.6,49.6)$ & 0.082 & $48.6(43.9,53.2)$ & $46.5(42.7,50.3)$ & 0.107 \\
\hline HbA1c (\%) & $9(8.8,9.1)$ & $8.8(8.7,9)$ & 0.177 & $8.6(8.4,8.8)$ & $8.8(8.7,9.0)$ & 0.102 \\
\hline $\begin{array}{l}\text { GAD-Ab } \\
\text { (IU/ml) }\end{array}$ & $4.5(4.2,4.9)$ & $5.6(5.2,6)$ & $\begin{array}{l}< \\
0.001\end{array}$ & $3.3(2.7,3.9)$ & $5.5(5.0,6.0)$ & $<0.001$ \\
\hline IA (\%) & $2.2(2.1,2.3)$ & $20.4(19.3,21.5)$ & $\begin{array}{l}< \\
0.001\end{array}$ & $0.3(0.3,0.3)$ & $27.8(26.7,29.3)$ & $<0.001$ \\
\hline $\begin{array}{l}\text { Hypertension } \\
(\%)\end{array}$ & $566(58.9)$ & $547(60.6)$ & 0.450 & 176(63.3) & $346(59.6)$ & 0.297 \\
\hline Fatty liver (\%) & $291(30.3)$ & $246(27.3)$ & 0.167 & $86(30.9)$ & 152(26.2) & 0.166 \\
\hline Cancer (\%) & $36(3.7)$ & $63(7)$ & 0.002 & $5(1.8)$ & $44(7.6)$ & $<0.001$ \\
\hline DKD (\%) & 191(19.9) & 207(22.9) & 0.113 & $55(19.8)$ & $124(21.3)$ & 0.654 \\
\hline $\begin{array}{l}\text { Neuropathy } \\
(\%)\end{array}$ & $257(26.7)$ & $273(30.3)$ & 0.100 & 72(25.9) & 168(28.9) & 0.372 \\
\hline $\begin{array}{l}\text { Retinopathy } \\
\text { (\%) }\end{array}$ & 263(27.4) & 258(28.6) & 0.570 & $79(28.4)$ & 178(30.6) & 0.525 \\
\hline $\begin{array}{l}\text { Atherosclerosis } \\
(\%)\end{array}$ & $662(68.9)$ & 638(70.7) & 0.391 & 188(67.6) & $416(71.6)$ & 0.233 \\
\hline \multicolumn{7}{|c|}{$\begin{array}{l}\text { Data are mean }(95 \% \mathrm{Cl}) \text { or number (percentage). IA, insulin antibody; BMI, body mass index; ALT, Alanine transferase; AST, } \\
\text { Aspartate transferase; LDL-C, low density lipoprotein cholesterol; HDL-c, high density lipoprotein cholesterol; FBG, fasting blood } \\
\text { glucose; } C P \text {, C peptide; HOMA2-IR, homeostasis model assessment } 2 \text { of insulin resistance; HOMA2- } \beta \text {, homeostasis model } \\
\text { assessment } 2 \text { of } \beta \text { cell function. HbA1c, hemoglobin; GAD-Ab, glutamic acid decarboxylase antibody. }\end{array}$} \\
\hline
\end{tabular}

Logistics regression analysis for risk factors of IA

To identify the factors that influenced IA levels, we performed a Logistics regression analysis, including factors which were different between IA positive and negative groups, such as age, diabetic duration, ALT, total cholesterol, triglyceride, LDL-c, FGB, GAD-Ab, HOMA2-IR, accompanied by cancer or smoking, and the kinds of oral hypoglycemic agents (OHAs) as independent variables. As a result, diabetic duration, ALT, triglyceride, FGB, GAD-Ab, kinds of OHAs, and cancer remained in the regression model and were significantly associated with IA levels ( $p$ all $<0.05$, Table 2 ). 
Table 2

Logistics regression analysis for risk factors of insulin antibodies.

\begin{tabular}{|lccc|}
\hline & OR & 95\% Confidence interval & $p$ value \\
\hline Diabetes duration & 1.019 & $1.001 \sim 1.037$ & 0.042 \\
\hline Kinds of OHAs & 0.875 & $0.771 \sim 0.991$ & 0.036 \\
\hline ALT & 0.996 & $0.992 \sim 1.000$ & 0.053 \\
\hline Triglyceride & 0.920 & $0.867 \sim 0.976$ & 0.005 \\
\hline FBG & 1.069 & $1.029 \sim 1.111$ & 0.001 \\
\hline GAD-Ab & 1.025 & $1.004 \sim 1.047$ & 0.021 \\
\hline With cancer & 0.533 & $0.310 \sim 0.917$ & 0.023 \\
\hline $\begin{array}{l}\text { OR, odds ratio; OHAs, oral hypoglycemic agents; ALT, Alanine transferase; FBG, fasting blood glucose; LDL-c, low density } \\
\text { lipoprotein cholesterol; GAD-Ab, glutamic acid decarboxylase antibody. }\end{array}$ \\
\hline
\end{tabular}

Distribution and IA levels of patients treated with different insulin regimens

The proportion of different insulin therapy among the patients with T2DM using insulin therapy were shown in Fig. 2A. Among the insulin therapy regimens with the population more than $1 \%$, glargine with OHAs was the most used (28.8\%), and the patients using biphasic insulin aspart 30/50 constituted the largest proportion of patients with positive IAs (13.7\%). The proportion of positive IAs was lowest in patients using glargine only (31.9\%) and highest in patients using human insulin only (70.3\%), p<0.001 (Fig. $2 \mathrm{~A}$ ). After adjusted diabetic duration, ALT, triglyceride, FGB, kinds of OHAs, and cancer, which were risk factors in the logistics regression, the ANCOVA test showed that among the different insulin therapy regimens, glargine induced lowest IA levels $(6.7[5.8,7.5]$, and insulin aspart caused highest IA levels (17.7[13.6,21.8] \%), $p<0.001$, Fig. 2B.

Effects of OHAs on IA levels.

Among the OHAs, a-glucosidase was the most used drug combined with insulin therapy (33.0\%), and the proportion of positive IAs was highest in patients using thiazolidinediones (TZDs) $(51.4 \%, p=0.121$, Fig. 3A). The IA levels in patients using sulfonylureas/glinides, metformin, and Dipeptidyl peptidase-4 (DPP-4) inhibitors were all significantly lower than in patients without these drugs (the controls were the patients using all the other OHAs and patients without any OHAs or glucagon-like peptide 1 receptor agonists (GLP-1RAs)) ( $p$ all <0.01, Fig. 3B), and patients using DPP-4 inhibitors had lowest IA level $(8.2[6.5,10.0]$ $\%$, Fig. 3B). After adjust diabetic duration, ALT, triglyceride, FGB, and cancer, ANCOVA test showed that the differences between the patients with or without these drugs remained significant (DPP-4 inhibitors, $p=0.026$; metformin, $p=0.002$; sulfonylureas/glinides, $p<0.001)$. The proportion of patients treated with OHAs was $83.0 \%$ in patients taking insulin glargine, which was only $51.4 \%$ in patients using mixed insulin (biphasic aspart, biphasic lispro and biphasic human insulin) in the present study $(p<0.001)$. On the other hand, the proportion of patients who were using glargine and deremir were similar in patients with different OHAs (42.0$55.1 \%)$ except sulfonylureas/glinides $(75.0 \%)(p<0.001$, Supplementary table 1$)$.

\section{Discussion}

The present study found that the positive IAs was significantly lower in patients using insulin glargine compared with the other insulin therapy regimens, while DPP-4 inhibitors, metformin, and insulin secretagogues may also have potential effects on reducing IA levels. As far as we are aware, there have not been any previous reports with such findings.

Although circulating IA rarely interfere with $\mathrm{HbA} 1 \mathrm{c}$ levels, FBG and insulin resistance was higher in patients with positive IA compared with the others in our study, and the result was in accordance with a previous study in patients with type 1 diabetes[16]. In the present study, increased HOMA2-IR in patients with positive IAs may contribute to the higher FBG rather than fasting Cpeptide. However, previous studies have demonstrated that insulin resistance may be a result of increased IAs[17, 18]. The problem of high FBG and insulin resistance is more pronounced and needs to be addressed in patients with T2DM, which may lead to increased insulin dose in these patients[17], and following increased financial cost on insulin and increased weight. Moreover, 
nearly half of the patients using insulin had positive IAs, which demonstrated the results of previous studies $[19,20]$. Therefore, attention should be paid to the detection of circulating IA level in patients with T2DM who are using insulin therapy, especially in elderly non-smokers with high LDL-c according to our study, and the choose of therapeutic regimen in patients with positive IAs is important.

In the previous studies, the proportions of positive IAs were 27.6-29\% in patients with glargine only [21, 22], and 24.5-49.2\% in patients using glargine plus aspart or lispro [10], which were lower than in patients with biphasic insulin aspart (68\%), biphasic human insulin (66\%) [14], and insulin detemir plus aspart (40-50\%) [23]. H Yki-Järvinen et al, found that antibodies against insulin glargine and human insulin were both significantly lower in patients treated with insulin glargine than in patients using neutral protamine hagedorn (NPH) [24], while the difference of IA levels between these two kinds of insulin was not statistically significant in patients with type 1 diabetes [25]. Moreover, Hattori et al. found that glargine and aspart induced insulin antibodies more frequently than the others based on a small sample size of 381 patients with T2DM, and only 17 patients were using glargine in their study (15). We confirmed that insulin glargine induced less IA than other insulin regimens for the first time in such a large population. The less IA induced by insulin glargine may contribute to its pharmacokinetic and pharmacodynamic characteristics: following the injection, insulin glargine forms a depot in the subcutaneous tissue, from which it is slowly absorbed. This provides a relatively uniform, peakless concentration over approximately $24 \mathrm{~h}$ after administration [26]. Therefore, treatment with insulin glargine resulted in a lower daily basal insulin dose and a lower number of injection site reactions than insulin detemir [27] and neutral protamine hagedorn [28]. Insulin degludec, another basal insulin with an ultra-long duration of action ( $>42 \mathrm{~h}$ ), has similar few immunogenic responses compared with insulin glargine [12]. However, there were only 7 patients ( $<1 \%$ of the population) using insulin degludec in the present study, and we did not include them in the statistical analysis of IA levels. On the other hand, the proportion of patients treated with $\mathrm{OHAs}$ was much higher in patients taking insulin glargine than in patients using mixed insulin in the present study. We demonstrated that the use of OHAs was a protective factor of IAs, which may also reduce IA levels in the patients using glargine.

We unexpectedly found that IA levels in patients using a-glucosidase and TZDs were similar with the patients who were not using these drugs, although they had similar effects on reduction of insulin resistance and insulin dose compared with metformin, DPP-4 inhibitors, and SGLT2 inhibitors [29-31]. Therefore, the association between OHAs and IA levels may not attribute to their effects on insulin dose reduction only. The elevation of endogenous insulin may play an important role in prevention of IA positiveness. Because our study showed that the combination of insulin secretion promoters was associated with declined IA levels in patients with T2DM. Moreover, Bae $\mathrm{J}$ et al, found that DPP-4 inhibitor users secreted more insulin than TZD users [32]. Their findings partially explained the decrease in IA levels in patients who were using insulin combined with DPP-4 inhibitors but not with TZDs in our study. Francesco et al, suggested that metformin could inhibit B cell activation and antibodies production in autoimmune diseases via increasing activation of Adenosine Monophosphate Activated Protein Kinase with subsequent decrease in phosphorylation of mTOR [33]. In the present study, low IA levels in patients using Sulfonylureas/glinides may correlated with the high proportion of long-acting insulin analogues in these patients. A case report showed that Liraglutide might also have effect on decreasing IA levels in patient with T2DM [34]. However, we did not observe this effect in patients with GLP-1RA due to the small number of patients taking the combination of GLP-1RA and insulin. Moreover, the number of patients using SGLT2 inhibitors was also too small and the reductive effect of SGLT2 inhibitor on IA levels needs to be further confirmed in a large sample size. Therefore, the mechanism of effects of different OHAs on IA levels is complex and needs further study.

In the present study, old age was the other relevant factor of IA levels except kinds of OHAs. The incidence and prevalence of many common autoimmune diseases are increased in the elderly despite autoimmune diabetes is more common in young people and child. Donna et al, suggested that aging is associated with a state of chronic inflammation and an increased likelihood of developing autoimmune diseases [35]. Aging affects negatively the immune system, defined as immunosenescence, which increases the susceptibility of elderly persons to infection, autoimmune disease, and cancer [36].

One limitation of our study was that the cross-sectional study could not explain the causality between the use of blood glucose lowering drugs and the change of IA levels. Other factors, such as duration of insulin use, age, and blood lipid levels, may simultaneously affect the drug prescription and IA levels. Moreover, we observed hospitalized patients with type 2 diabetes in the present study, most of whom had poor glycemic control. The association between IA levels and glucose-lowering drugs in insulintreated patients with good glycemic control needs further study. 


\section{Conclusions}

In conclusion, IA levels should be tested in patients with T2DM who are using insulin therapy, especially in elderly non-smokers with lipid metabolic disorder. The use of insulin glargine, DPP-4 inhibitors, metformin, insulin secretagogues, and SGLT2 inhibitors were associated with lower IA levels, which may be considered in patients with T2DM who need insulin therapy, especially those who had positive IAs. The causal relationships between changes of IA levels and these drugs need further study.

\section{Declarations}

\section{Acknowledgments}

We thank the members of Endocrinology department of Nanjing First hospital for their support.

\section{Data Availability Statement}

The datasets generated during and/or analyzed during the current study are available from the corresponding author on reasonable request.

\section{Author Disclosure statement:}

The authors have nothing to disclose.

\section{Funding}

This study was supported by the National Key R\&D Program of China (No. 2018YFC1314103), the National Natural Science Foundation of China (No. 81870563), and Science Foundation of Nanjing Public Health Bureau (YKK17107).

\section{References}

1. A. American Diabetes, 9. Pharmacologic Approaches to Glycemic Treatment: Standards of Medical Care in Diabetes-2019, Diabetes Care, 42 (2019) S90-S102.

2. B.M. Brooks-Worrell, D. Nielson, J.P. Palmer, Insulin autoantibodies and insulin antibodies have similar binding characteristics, Proc Assoc Am Physicians, 111 (1999) 92-96.

3. D. Bortolotti, I. Mothe-Satney, P. Ferrari, N. Gautier, J. Sonke, S. Palle, G. Bernard, J.L. Badetti, A. Fredenrich, E. Van Obberghen, B. Canivet, Spontaneous hypoglycaemia in the presence of both anti-insulin antibody and anti-insulin receptor antibody, Diabetes Metab, 32 (2006) 598-603.

4. R.P. Radermecker, E. Renard, A.J. Scheen, Circulating insulin antibodies: influence of continuous subcutaneous or intraperitoneal insulin infusion, and impact on glucose control, Diabetes Metab Res Rev, 25 (2009) 491-501.

5. J. Zhu, L. Yuan, W.J. Ni, Y. Luo, J.H. Ma, Association of Higher Circulating Insulin Antibody with Increased Mean Amplitude Glycemic Excursion in Patients with Type 2 Diabetes Mellitus: A Cross-Sectional, Retrospective Case-Control Study, J Diabetes Res, 2019 (2019) 7304140.

6. A. Forbes, T. Murrells, H. Mulnier, A.J. Sinclair, Mean HbA1c, HbA1c variability, and mortality in people with diabetes aged 70 years and older: a retrospective cohort study, Lancet Diabetes Endocrinol, 6 (2018) 476-486.

7. H.Y. Jin, K.A. Lee, T.S. Park, The impact of glycemic variability on diabetic peripheral neuropathy, Endocrine, 53 (2016) 643-648.

8. X. Wang, X. Zhao, T. Dorje, H. Yan, J. Qian, J. Ge, Glycemic variability predicts cardiovascular complications in acute myocardial infarction patients with type 2 diabetes mellitus, Int J Cardiol, 172 (2014) 498-500.

9. B.O. Boehm, J.A. Vaz, L. Brondsted, P.D. Home, Long-term efficacy and safety of biphasic insulin aspart in patients with type 2 diabetes, Eur J Intern Med, 15 (2004) 496-502.

10. P. Home, K.M. Derwahl, M. Ziemen, K. Wernicke-Panten, S. Pierre, Y. Kirchhein, S.K. Garg, Anti-Insulin Antibodies and Adverse Events with Biosimilar Insulin Lispro Compared with Humalog Insulin Lispro in People with Diabetes, Diabetes Technol Ther, 20 (2018) 160-170. 
11. L.L. Ilag, T.M. Costigan, M.A. Deeg, R.K. Pollom, C.L. Chang, R.J. Konrad, M.J. Prince, Clinical Outcomes of Patients with Diabetes Who Exhibit Upper-Quartile Insulin Antibody Responses After Treatment with LY2963016 or Lantus((R)) Insulin Glargine, Diabetes Ther, 8 (2017) 545-554.

12. J. Vora, J. Seufert, H. Solberg, O. Kinduryte, T. Johansen, P. Hollander, Insulin degludec does not increase antibody formation versus insulin glargine: an evaluation of phase Illa trials, Diabetes Obes Metab, 18 (2016) 716-720.

13. L.G. Delogu, S. Deidda, G. Delitala, R. Manetti, Infectious diseases and autoimmunity, J Infect Dev Ctries, 5 (2011) 679-687.

14. A. Lindholm, L.B. Jensen, P.D. Home, P. Raskin, B.O. Boehm, J. Rastam, Immune responses to insulin aspart and biphasic insulin aspart in people with type 1 and type 2 diabetes, Diabetes Care, 25 (2002) 876-882.

15. B.M. Duvivier, N.C. Schaper, M.K. Hesselink, L. van Kan, N. Stienen, B. Winkens, A. Koster, H.H. Savelberg, Breaking sitting with light activities vs structured exercise: a randomised crossover study demonstrating benefits for glycaemic control and insulin sensitivity in type 2 diabetes, Diabetologia, 60 (2017) 490-498.

16. V. Burkart, K. Strassburger, F. Zivehe, D. Markgraf, C. Herder, K. Mussig, J. Szendroedi, N. Schloot, M. Roden, G.D.S. Group, Inverse association of insulin antibody levels with insulin sensitivity in adults with Type 1 diabetes, Diabet Med, 35 (2018) 595601.

17. H.N. Kim, B. Fesseha, L. Anzaldi, A. Tsao, P. Galiatsatos, A. Sidhaye, Antibody-Mediated Extreme Insulin Resistance: A Report of Three Cases, Am J Med, 131 (2018) 102-106.

18. A.B. Kurtz, J.D. Nabarro, Circulating insulin-binding antibodies, Diabetologia, 19 (1980) 329-334.

19. G. Schernthaner, Immunogenicity and allergenic potential of animal and human insulins, Diabetes Care, 16 Suppl 3 (1993) 155-165.

20. N. Hattori, M.R. Duhita, A. Mukai, M. Matsueda, A. Shimatsu, Development of insulin antibodies and changes in titers over a long-term period in patients with type 2 diabetes, Clin Chim Acta, 433 (2014) 135-138.

21. P.A. Hollander, W.L. Carofano, R.L.H. Lam, G.T. Golm, R. Eldor, M.F. Crutchlow, M.C. Marcos, M.S. Rendell, P.D. Home, B. Gallwitz, J. Rosenstock, Efficacy and safety of MK-1293 insulin glargine compared with originator insulin glargine (Lantus) in type 2 diabetes: A randomized, open-label clinical trial, Diabetes Obes Metab, 20 (2018) 2229-2237.

22. R.K. Pollom, L.L. llag, L.B. Lacaya, T.M. Morwick, R. Ortiz Carrasquillo, Lilly Insulin Glargine Versus Lantus((R)) in Insulin-Naive and Insulin-Treated Adults with Type 2 Diabetes: A Randomized, Controlled Trial (ELEMENT 5), Diabetes Ther, 10 (2019) 189203.

23. N. Thalange, A. Bereket, L.B. Jensen, L.C. Hiort, V. Peterkova, Development of Insulin Detemir/Insulin Aspart Cross-Reacting Antibodies Following Treatment with Insulin Detemir: 104-week Study in Children and Adolescents with Type 1 Diabetes Aged 2-16 Years, Diabetes Ther, 7 (2016) 713-724.

24. H. Yki-Jarvinen, A. Dressler, M. Ziemen, H.O.E.s.S. Group, Less nocturnal hypoglycemia and better post-dinner glucose control with bedtime insulin glargine compared with bedtime NPH insulin during insulin combination therapy in type 2 diabetes. HOE 901/3002 Study Group, Diabetes Care, 23 (2000) 1130-1136.

25. P.D. Home, R. Rosskamp, J. Forjanic-Klapproth, A. Dressler, G. European Insulin Glargine Study, A randomized multicentre trial of insulin glargine compared with NPH insulin in people with type 1 diabetes, Diabetes Metab Res Rev, 21 (2005) 545-553.

26. M. Lepore, S. Pampanelli, C. Fanelli, F. Porcellati, L. Bartocci, A. Di Vincenzo, C. Cordoni, E. Costa, P. Brunetti, G.B. Bolli, Pharmacokinetics and pharmacodynamics of subcutaneous injection of long-acting human insulin analog glargine, NPH insulin, and ultralente human insulin and continuous subcutaneous infusion of insulin lispro, Diabetes, 49 (2000) 2142-2148.

27. S.G. Swinnen, A.C. Simon, F. Holleman, J.B. Hoekstra, J.H. Devries, Insulin detemir versus insulin glargine for type 2 diabetes mellitus, Cochrane Database Syst Rev, (2011) CD006383.

28. A. Fiesselmann, T. Wiesner, H. Fleischmann, P. Bramlage, Real-world therapeutic benefits of patients on insulin glargine versus NPH insulin, Acta Diabetol, 53 (2016) 717-726.

29. W. Yang, J. Liu, Z. Shan, H. Tian, Z. Zhou, Q. Ji, J. Weng, W. Jia, J. Lu, J. Liu, Y. Xu, Z. Yang, W. Chen, Acarbose compared with metformin as initial therapy in patients with newly diagnosed type 2 diabetes: an open-label, non-inferiority randomised trial, Lancet Diabetes Endocrinol, 2 (2014) 46-55.

30. H. Yilmaz, A. Gursoy, M. Sahin, N. Guvener Demirag, Comparison of insulin monotherapy and combination therapy with insulin and metformin or insulin and rosiglitazone or insulin and acarbose in type 2 diabetes, Acta Diabetol, 44 (2007) 187-192.

Page 10/13 
31. W. Yang, X. Cai, X. Gao, Y. Chen, L. Chen, L. Ji, Addition of dipeptidyl peptidase-4 inhibitors to insulin treatment in type 2 diabetes patients: A meta-analysis, J Diabetes Investig, 9 (2018) 813-821.

32. J. Bae, G. Kim, Y.H. Lee, B.W. Lee, E.S. Kang, B.S. Cha, Differential Effects of Thiazolidinediones and Dipeptidyl Peptidase-4 Inhibitors on Insulin Resistance and beta-Cell Function in Type 2 Diabetes Mellitus: A Propensity Score-Matched Analysis, Diabetes Ther, 10 (2019) 149-158.

33. F. Ursini, E. Russo, G. Pellino, S. D'Angelo, A. Chiaravalloti, G. De Sarro, R. Manfredini, R. De Giorgio, Metformin and Autoimmunity: A "New Deal" of an Old Drug, Front Immunol, 9 (2018) 1236.

34. H. Hirai, E. Ogata, N. Kikuchi, T. Kohno, N. Machii, K. Hasegawa, T. Watanabe, H. Satoh, The effects of liraglutide on both hypereosinophilic insulin allergy and the characteristics of anti-insulin antibodies in type 2 diabetes mellitus: a case report, $\mathrm{J}$ Med Case Rep, 10 (2016) 202.

35. D. Ray, R. Yung, Immune senescence, epigenetics and autoimmunity, Clin Immunol, 196 (2018) 59-63.

36. H. Cao Dinh, I. Beyer, T. Mets, O.O. Onyema, R. Njemini, W. Renmans, M. De Waele, K. Jochmans, S. Vander Meeren, I. Bautmans, Effects of Physical Exercise on Markers of Cellular Immunosenescence: A Systematic Review, Calcif Tissue Int, 100 (2017) 193-215.

\section{Figures}

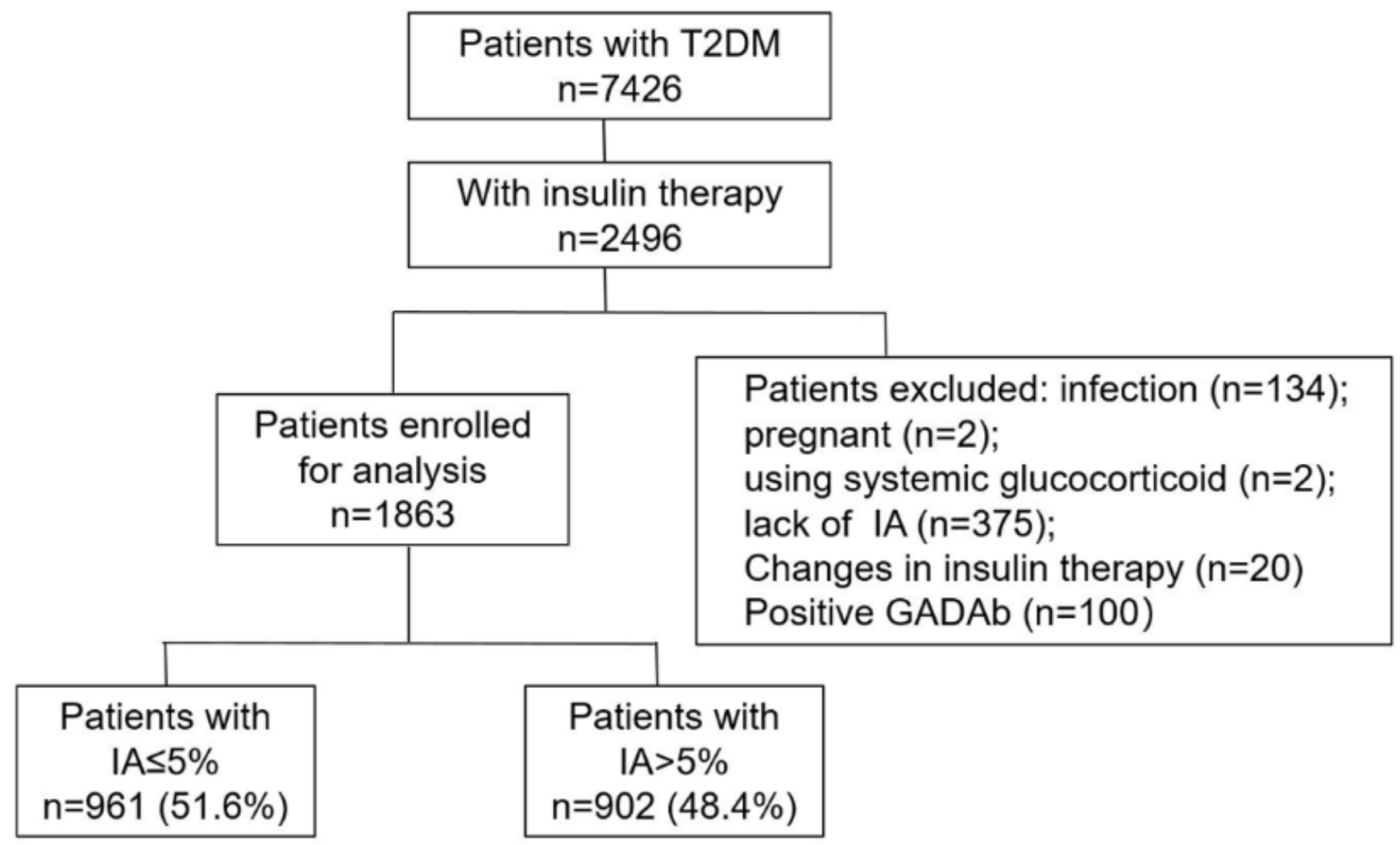

Figure 1

Flow diagram of patients screening.

T2DM, type 2 diabetes; IA, insulin antibody; GADAb, glutamic acid decarboxylase antibody. 
A

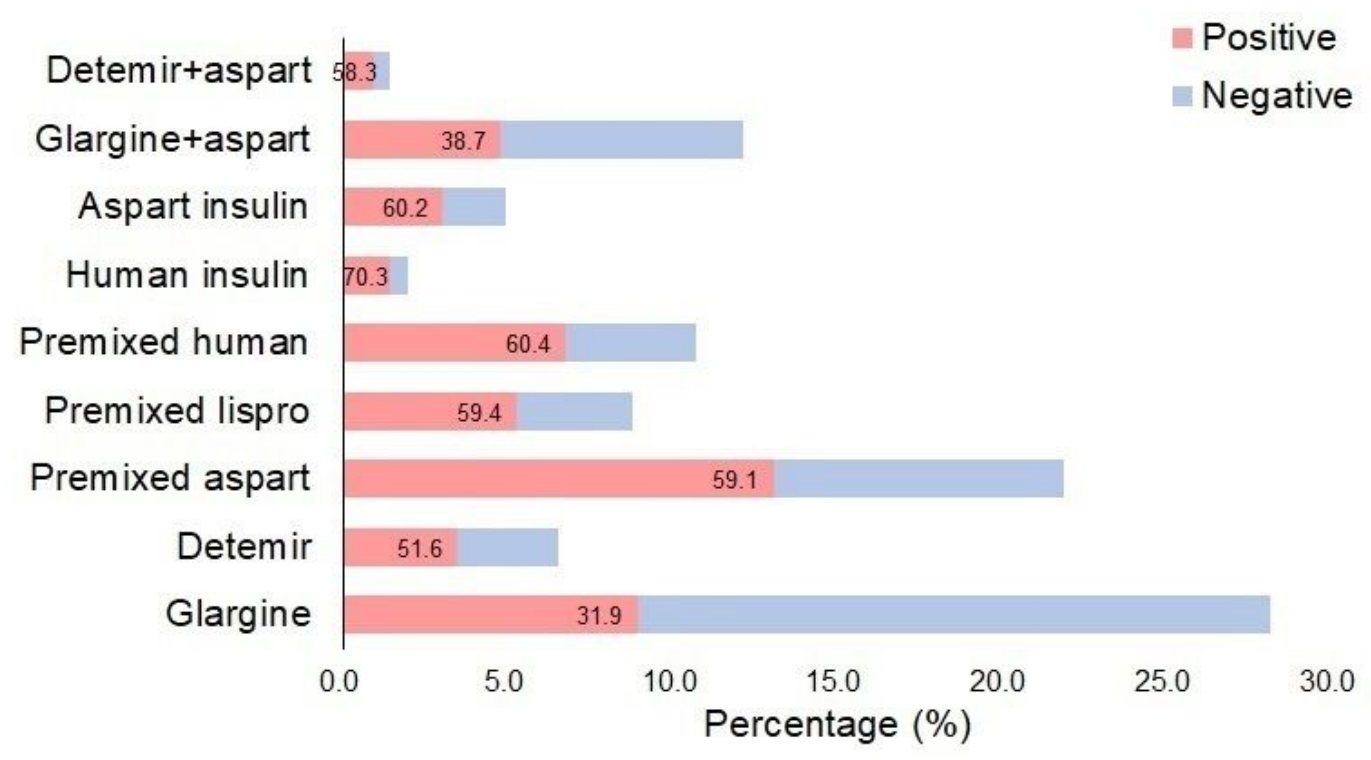

B

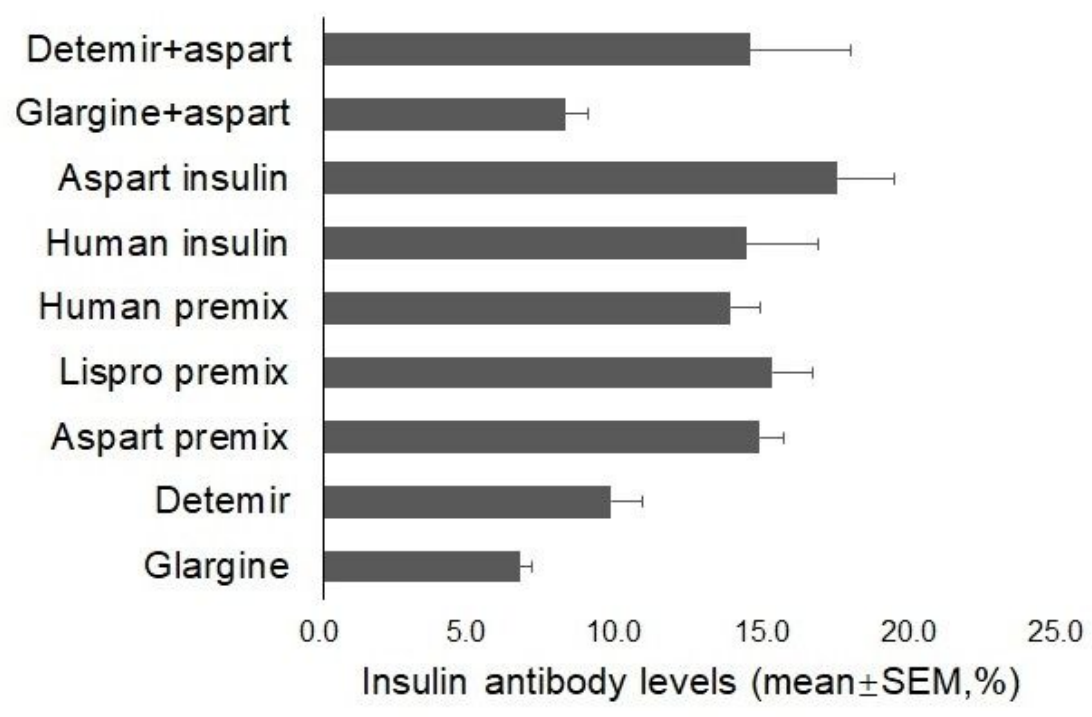

Figure 2

The insulin antibody (IA) levels in patients using different insulin regimens.

A. Percentage of patients using different insulin regimens, and the proportion of positive IAs (red bar) in patients using different insulin regimens. B. IA levels in patients using different insulin regimens. 


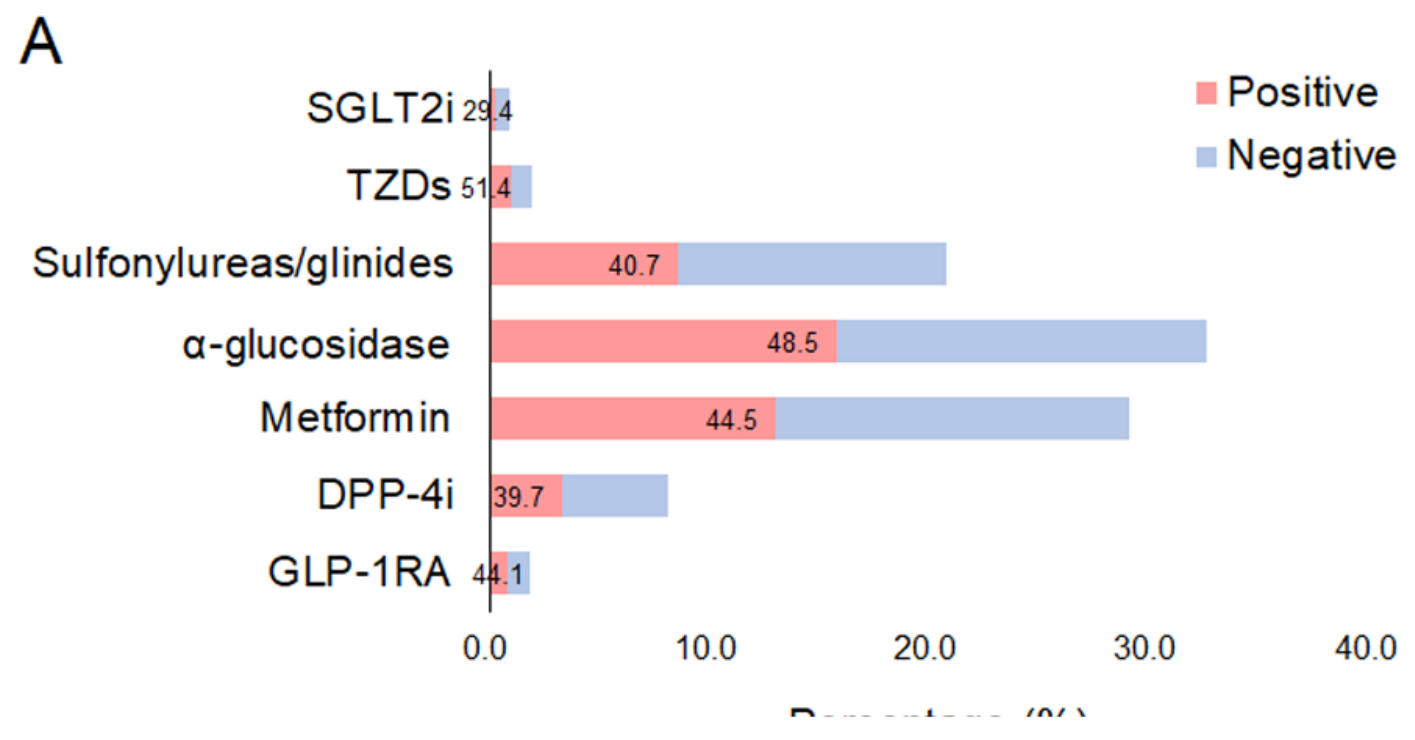

Figure 3

The insulin antibody (IA) levels in patients using different oral hypoglycemic agents (OHAs) and GLP-1RAs.

A. Proportion of patients using different OHAs and the rate of positive IAs (red bar) in patients using different drugs. B. IA levels in patients using different OHAs and GLP-1RAs. *, vs patients not using the drug, $p<0.01$.

\section{Supplementary Files}

This is a list of supplementary files associated with this preprint. Click to download.

- SupplementaryTable1.docx 